\title{
Prediction of the Development of Hepato-Cellular-Carcinoma in Patients with Liver Cirrhosis by the Serial Determinations of Serum Alpha-L-fucosidase Activity
}

\author{
Hideo Ishizuka ${ }^{* * *}$, Tomoki Nakayama**, Shunichi MatsuokA**, Iori Gotoh**, Masahiro OgawA**, \\ Kazutomo Suzuki**, Naohide Tanaka**, Kouji Tsubaki**, Hitoshi OhKubo**, \\ Yasuyuki AraKawa** and Tadao OKano*
}

\begin{abstract}
Objective Evaluation of the usefulness of the serial daterminations of serum alpha-L-fucosidase (AFU) activity for prediction of the development of hepatocellular carcinoma (HCC) was performed. Methods and Patients Serum AFU activity was determined monthly for 42 months in 73 patients with liver cirrhosis (LC). Results HCC was diagnosed in 27 patients by means of ultrasonography during this observation period. In 23 (85\%) of the 27 patients, serum AFU activity was found to exceed $700 \mathrm{nmole} / \mathrm{ml} / \mathrm{h}$ during the LC stage. HCC developed within a few years in 23 $(82 \%)$ of $28 \mathrm{LC}$ patients with AFU activity exceeding $700 \mathrm{nmole} / \mathrm{ml} / \mathrm{h}$, in contrast, it developed in only 4 (9\%) of $45 \mathrm{LC}$ patients with AFU activity below $700 \mathrm{nmole} / \mathrm{ml} / \mathrm{h}$. AFU activity was already elevated in $23(85 \%)$ of 27 patients at least 6 months before the detection of HCC by ultrasonography. Conclusion It is conceivable that the development of HCC can be predicted by means of serial determinations of serum AFU activity in patients with $L C$.
\end{abstract}

(Internal Medicine 38: 927-931, 1999)

Key words: exoglucosidase, tumor marker, early diagnosis of HCC

\section{Introduction}

Elevated levels of alpha-L-fucosidase (AFU) have been reported in patients with hepatocellular carcinoma (HCC) (18 ). We have reported the usefulness of the determination of serum AFU activity as a new tumor marker in the diagnosis of HCC (9). Previously, patients with an AFU activity exceeding $700 \mathrm{nmole} / \mathrm{ml} / \mathrm{h}$ who had not developed $\mathrm{HCC}$ were regarded as false-positives; it later became evident that $\mathrm{HCC}$ developed at a high incidence in these patients. Therefore, it is conceivable that such cases are not false-positives but actually are in the very early stages of HCC. To substantiate this assumption, a prospective study is needed. The present study therefore, was conducted to evaluate the usefulness of serial determinations of serum AFU activity in LC patients for the prognostication of developing HCC. We attempted to clarify whether the development of $\mathrm{HCC}$ can be predicted from the dynaics of serum AFU activities in patients with LC, and if so, whether prediction by this method can be made earlier than the detection of HCC with ultrasonography.

\section{Subjects and Methods}

Serum AFU activities were determined at monthly intervals in $73 \mathrm{LC}$ patients $(\mathrm{HCC}$ was not yet detectable by ultrasonographies performed by 2 physicians with at least 10 years of experience with abdominal ultrasonogrraphical diagnostic techiniques). Determinations were performed in the Clinic of Internal Medicine of Surugadai Nihon University Hospital, Tokyo, from April 1994 to September 1997.

These patients were followed by ultrasonography (Aloca) every 3 months for from 8 months to 3.5 years. Subjects consisted of 58 patients with C type LC, 12 with B type LC, and 3 with non-B non-C type LC. Serum AFU activity was assayed by a modified method of Zielke et al (10). In brief, $10 \mu \mathrm{l}$ of serum was added to $100 \mu \mathrm{l}$ of $1 \mathrm{mmole} / \mathrm{L}$ p-nitrophenyl- $\alpha-\mathrm{L}$ fucopyranoside dissolved in $150 \mathrm{mmole} / \mathrm{l}$ citrate-phosphate buffer (pH 5) containing $0.05 \mathrm{mg} / \mathrm{ml} \mathrm{BSA}$. This solution was incubated at $37^{\circ} \mathrm{C}$ for 1 hour, and the reaction was stopped by the addition of $100 \mu \mathrm{l}$ of $0.2 \mathrm{~N} \mathrm{NaOH}$. The absorbance of $\mathrm{p}$ nitrophenol was read at $405 \mathrm{~nm}$, and the enzyme activity was expressed as nano-moles of p-nitrophenyl- $\alpha$-L-fuco-pyrano-

From *Toubu Chiiki Hospital, Tokyo and **the Third Department of Internal Medicine, Nihon University, Tokyo

Received for publication September 29, 1998; Accepted for publication July 14, 1999

Reprint requests should be addressed to Dr. Hideo Ishizuka, the Vice-Director of Toubu Chiiki Hospital, 5-14-1, Kameari, Katsushikaku, Tokyo 125-8512 
side cleaved per milliliter per hour at $37^{\circ} \mathrm{C}$.

\section{Statistical analysis}

Data were analyzed by Student's unpaired t-test and differences were considered significant at $\mathrm{p}<0.05$.

\section{Results}

During the observation period, HCC developed in 27 out of 73 patients with LC.

In $23(85 \%)$ of those 27 cases, AFU activities were already elevated up to $700 \mathrm{nmole} / \mathrm{ml} / \mathrm{h}$, during the LC stage. Though the incidence of HCC was very high in LC patients with an AFU activity exceeding $700 \mathrm{nmole} / \mathrm{ml} / \mathrm{h}$ (23 (82\%) of 28 patients), HCC developed in only $4(9 \%)$ of 45 LC patients with AFU activity below $700 \mathrm{nmole} / \mathrm{ml} / \mathrm{h}$ (Fig. 1).

Figure 2 shows the chronological changes in AFU activity in patients with $\mathrm{LC}$ who developed $\mathrm{HCC}$, during the 42-month observation period: In 23 (85\%) of 27 LC patients, AFU activity increased to $700 \mathrm{nmole} / \mathrm{ml} / \mathrm{h}$ at least 6 months before HCC

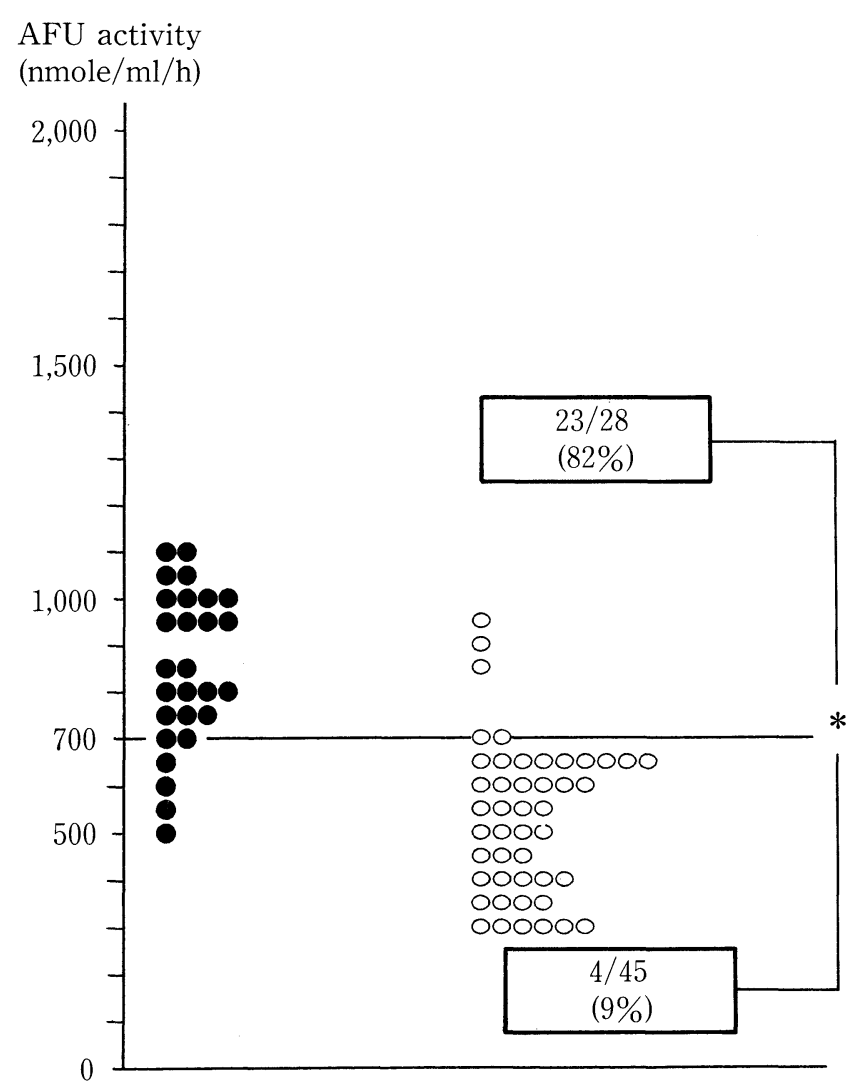

Figure 1. Relation between the incidence of development of HCC and AFU activity during the LC stage. The incidence of development of HCC was significantly higher in LC patients with an AFU activity exceeding $700 \mathrm{nmole} / \mathrm{ml} / \mathrm{h}$ than in those with an AFU activity below $700 \mathrm{nmole} / \mathrm{ml} / \mathrm{h}$. O: Accompanying HCC, $\bigcirc$ : No accompanying HCC. AFU: alpha-L-fucosidase, HCC: hepatocellular carcinoma, LC: liver cirrhosis *: p $<0.01$ was detected by ultrasonography. In the remaining 4 patients, AFU activity did not rise until HCC was detected. Elevation of AFU activity occurred 3 years or more before the detection of HCC in 4 patients, 2 years or more before in 7 patients, 1 year or more before in 17 patients, and 6 months or more before in 23 patients. AFU activity stayed at high levels after the initial elevation in 17 of 23 patients, but in the remaining 6 cases fell to less than $700 \mathrm{nmole} / \mathrm{ml} / \mathrm{h}$, and then rose again before the detection of HCC. In 3 of 4 patients who maintained low levels of AFU activity and accompanying HCC, AFU activity was below $700 \mathrm{nmole} / \mathrm{ml} / \mathrm{h}$, when the HCC was detected.

The dynamics of AFU activity in the LC patients who did not develop HCC during the observation period are shown in Fig. 3. Except for 3 of the 45 cases (indicated by AFU activities were maintained at low levels below 700 nmole/ $\mathrm{ml} / \mathrm{h}$. Figure 4 shows the ultrasonographic images of HCC which had high levels of AFU before being diagnosed as HCC. Eleven $(48 \%)$ of the 23 HCCs were solitary and less than 20 $\mathrm{mm}$ in diameter.

\section{Discussion}

AFU is an exoglucosidase which exists in the liver, kidney, and epididymis, of mammalian species and catabolizes the fucose-containing sugar proteins (11).

The mechanism of the elevation of serum AFU activity in patients with HCC is still obscure. One possibility is an increase in protein synthesis by the neoplasm with a consequent increase in fucose turnover (1). This possibility, however, is not supported by recent reports showing significantly low AFU levels in HCC tissue compared with nontumoral liver tissue (5), and similar levels of AFU activity in the culture supernatants of HCC cell lines and Chang liver cells(8).

It is well known that sugar chains of sugar proteins vary in the course of carcinogenesis. In hepatocarcinogenesis, for example, fucosylation of some sugar proteins increases, and this increase of fucosylation may lead to the elevated alpha-Lfucosidase activity.

Whether this speculation is true or not, serum AFU activity is significantly higher in patients with HCC than in those with LC and chronic hepatitis, and we have reported the sensitivity of serum AFU activity in the detection of HCC and its specificity of $96 \%$, and $75 \%$ (cut-off level $=700 \mathrm{nmole} / \mathrm{ml} / \mathrm{h}$ ). (unpublished personal data), this sensitivity is not sufficiently high to serve as a marker for HCC, however, HCC did develop in LC patients with a high AFU activity at a high incidence rate following the above report. These findings led us to add a prospective study for clarifying the relationship between serum AFU activity and the development of HCC in LC patients.

One of the purposes of this study was to detect when serum AFU activity starts to become elevate in patients with LC, a high risk group for HCC. Computed tomography, magnetic resonance imaging and ultrasonography have been used to detect $\mathrm{HCC}$, with ultrasonography being the most practical and reliable technique to detect early HCC. However, it is still difficult to detect small isoechogenic HCC (12-15). Although al- 


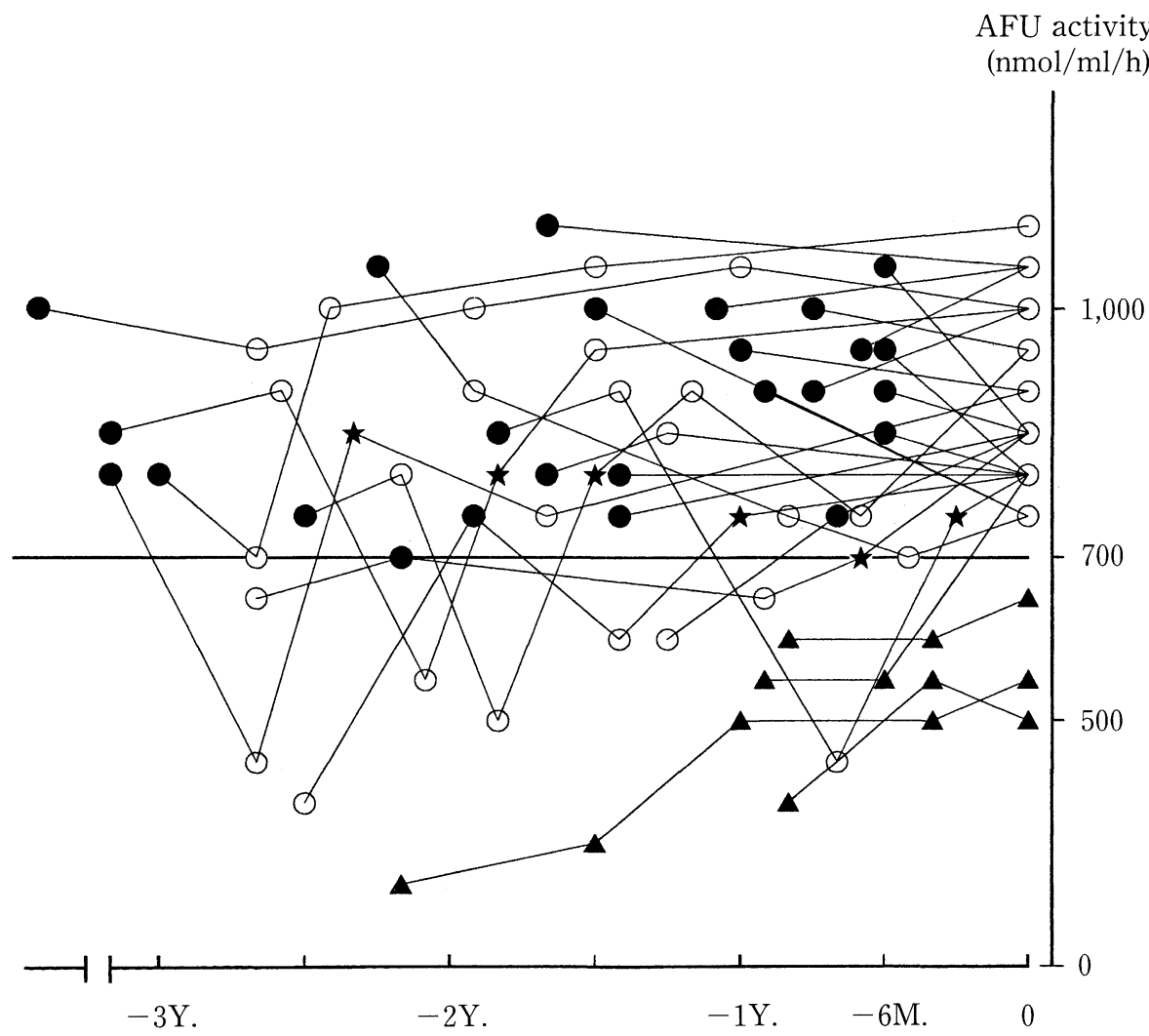

Figure 2. Dynamics of AFU activities of LC patients who developed HCC. AFU activities increased up to $700 \mathrm{nmole} / \mathrm{ml} / \mathrm{h}$ at least temporarily until HCC was detected in 23 of 27 LC patients who developed HCC. These elevations of AFU activities occurred at least 6 months before the detection of HCC. : The point of the initial elevation of AFU activity up to $700 \mathrm{nmole} / \mathrm{ml} / \mathrm{h}$, $\star$ : The point of re-elevation of $A F U$ activity up to $700 \mathrm{nmole} / \mathrm{ml} / \mathrm{h}$, $\Delta-\Delta$ : Cases in which HCC developed without elevation of AFU activity up to $700 \mathrm{nmole} /$ $\mathrm{ml} / \mathrm{h}$. 0: The point of the initial detection of HCC by ultrasonography, -: before AFU: alpha-L-fucosidase, HCC: hepatocellular carcinoma, LC: liver cirrhosis, M: month(s), Y: year(s).

pha-fetoprotein (AFP) is the most useful marker for HCC, this marker is not very sensitive for the detection of early HCC $(16,17)$. It has been reported that there are some isoforms of AFP differentiated by its difference of sugar chains (18-20). It was recently reported that the AFP isoform, as analyzed by lectin affinity immunoblotting, is useful for preclinical diagnosis of HCC $(21,22)$. An AFP level exceeding $100 \mathrm{ng} / \mathrm{ml}$ is required to detect AFP isoforms, but AFP is usually not too highly elevated in the early stages of HCC.

In contrast, AFU activity is not related to the tumor size (8). Further, in this study, AFU activity rose before the HCC was detectable by ultrasonography in about $85 \%$ of the patients with LC associated HCC. LC patients with AFU activity exceeding $700 \mathrm{nmole} / \mathrm{ml} / \mathrm{h}$ tended to develop HCC at a high incidence and in a short interval. Conversely, patients with LC who maintained low levels of AFU activity infrequently developed HCC.

It is unclear why AFU activity remained low in 3 cases of HCC. It may be due to changes of sugar chain of sugar protein accompanying the development of HCC not occurring in only fucose.

The fact that $48 \%$ of the HCCs which were discovered by elevation of AFU in the LC stage were the so-called small hepatic cancer, strongly suggests the usefulness of monitoring AFU levels in LC patients in order to establish an early diagnosis of $\mathrm{HCC}$.

In conclusion, serial determinations of serum AFU activity in patients with $\mathrm{LC}$ were helpful to predict the development of HCC. Physicians should recognize that patients with LC with high AFU activities are a super-high risk group for $\mathrm{HCC}$ and should perform diagnostic imaging studies at least once a month. If HCC is suspected in these patients, further examination (i.e. hepatic angiography, tumor biopsy etc.) must be performed. By doing so, $\mathrm{HCC}$ is likely to be detected at a very early stage, and it would be expected that the prognosis of $\mathrm{HCC}$ would improve. 


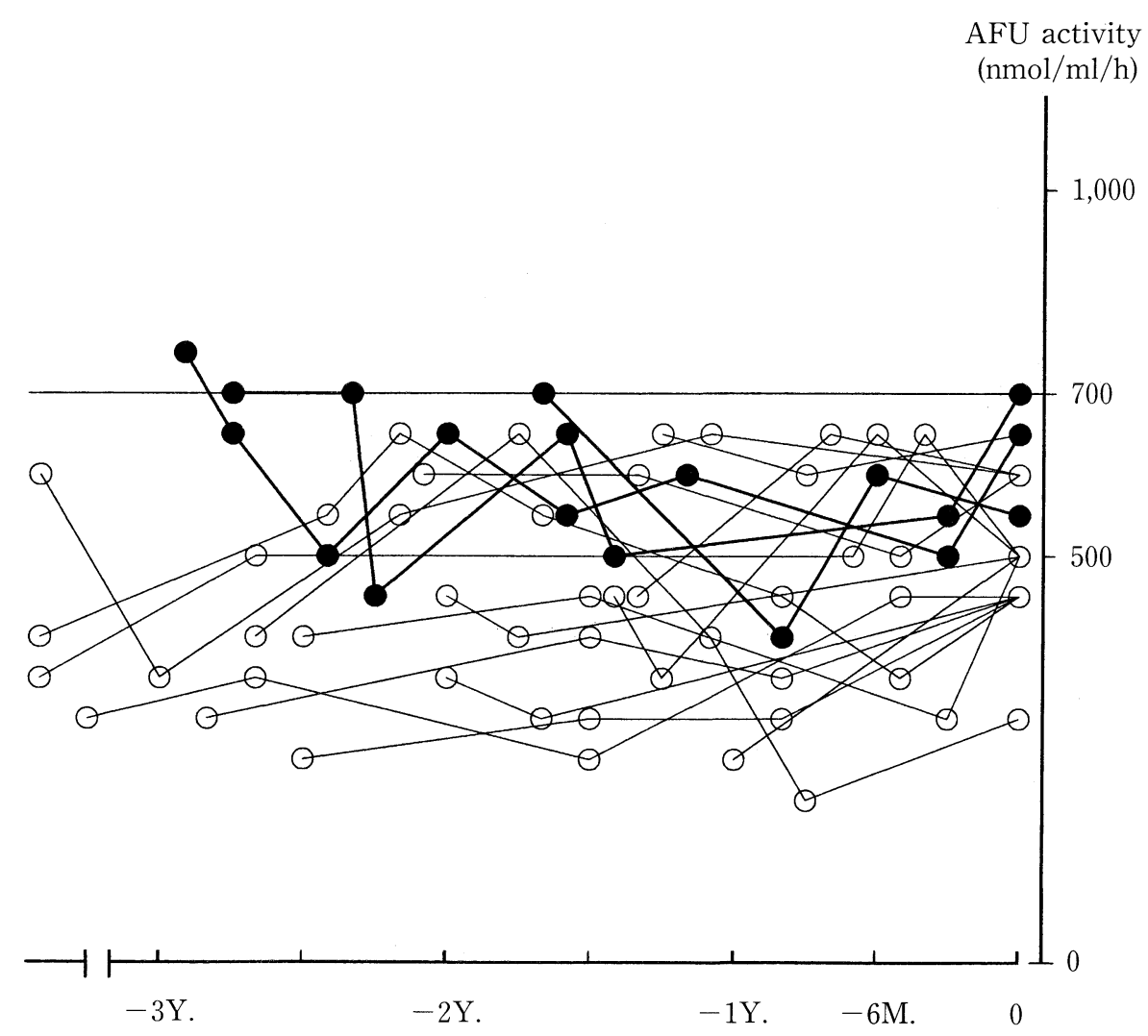

Figure 3. Dynamics of AFU activities in LC patients who did not develop HCC. AFU activity levels remained at low levels during the observation period in all but 3 patients indicated by 0 . 0: The point at the end of the observation period. -: before. AFU: alpha-L-fucosidase, HCC: hepatocellular carcinoma, LC: liver cirrhosis, M: month(s), Y: year(s).

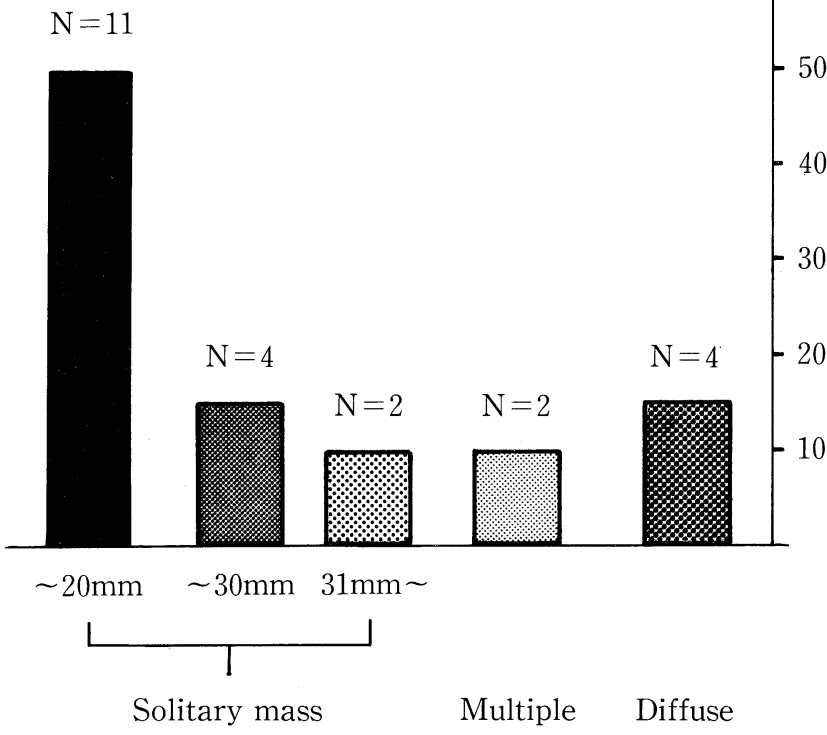

Acknowledgements: We would like to express our special thanks to Dr. Y. Tsukada and Mr. N. Hibi in the SRL Laboratory for the determination of AFU activity, and to Dr. M. Itoh in the Department of Neurosurgery of our hospital for his helpful advice.

\section{References}

1) Deugnier Y, David V, Bressot P, et al. Serum $\alpha$-L-fucosidase: a new marker for the diagnosis of primary hepatic carcinoma? Hepatology 4: 889, 1984.

2) Di Cioccio RA, Barlow JJ, Motta KL. Evaluation of alpha-L-fucosidase as a marker of primary liver cancer. IRCS Med Sci 13: 849-850, 1985.

3) Deugnier Y, David V, Leray G, Blayau M, Le Gall JY. Biological markers in hepatocellular carcinoma. Ann Biol Clin (Paris) 46: 85-88, 1988.

4) Bukofzer S, Stass PM, Kew MC, de Beer M, Groeneveld HT. Alpha-Lfucosidase as a serum marker of hepatocellular carcinoma in southern African blacks. Br J Cancer 59: 417-420, 1989.

5) Leray G, Deugnier Y, Jouanolle A-M, et al. Biochemical aspects of $\alpha$-Lfucosidase in hepatocellular carcinoma. Hepatology 9: 249-252, 1989.

6) Hutchinson WL, Johnson PJ, Du M-Q, Williams R. Serum and tissue $\alpha$ L-fucosidase activity in the pre-clinical and clinical stages of hepatocel-

Figure 4. Ultrasonographic figures of HCC discovered by the elevation of AFU activity in the stage of LC. Eleven of the 23 HCCs were solitary and less than $20 \mathrm{~mm}$ in diameter, the socalled small hepatic cancer. 


\section{Early Diagnosis of HCC by AFU}

lular carcinoma. Clin Sci (Colch) 81: 177-182, 1991.

7) Giardina MG, Matarazoo M, Varriale A, Morante R, Napoli A, Martino R. Serum alpha-L-fucosidase. A useful marker in the diagnosis of hepatocellular carcinoma. Cancer 70: 1044-1048, 1992.

8) Takahashi H, Saibara T, Iwamura S, et al. Serum $\alpha$-L-fucosidase Activity and Tumor Size in Hepatocellular Carcinoma. Hepatology 19: 1414-1417, 1994.

9) Ishizuka H, Nakayama T, Matsuoka S, et al. Significanse of the determination of AFU activity for early diagnosis of HCC. Proceedings of 93 th. Annual meeting of the Japanese society of Internal Medicine, Osaka, 1996.

10) Zielke K, Okada S, O Brien JS. Fucosidosis: diagnosis by serum assay of alpha-L-fucosidase. J Lab Clin Med 79: 164-169, 1972.

11) Tettamenti G, Masserini M, Goi G, Lombardo A. Alpha-l-fucosidase. in: Methods of Enzymatic Analysis, 3rd ed. Vol 4. Bergmyer HU, Ed. Verlag Chemie., Basel, 1963: 263-269.

12) Shinagawa $T$, Ohto $M$, Kimura $K$, et al. Diagnosis and clinical features of small hepatocellular carcinoma with emphasis on the utility of real-time ultrasonography: a study in 51 patients. Gastroenterology 86: 495-502, 1984.

13) Kobayashi K, Sugimoto T, Makino H, et al. Screening methods for early detection of hepatocellular carcinoma. Hepatology 5: 1100-1105, 1985.

14) Okuda K. Early recognition of hepatocellular carcinoma. Hepatology 6 : 729-738, 1986.
15) Chen DS. Early diagnosis of primary liver cancer. Ital J Gastroenterol 20: 287-290, 1989.

16) Maringhini A, Cottone M, Scicarrino E, et al. Ultrasonography and alpha-feto-protein in diagnosis of hepatocellular carcinoma in cirrhosis. Dig Dis Sci 33: 47-51, 1988.

17) Lok AS, Lai CL. $\alpha$-Fetoprotein monitoring in Chinese patients with chronic hepatitis B virus infection: role in the early detection of hepatocellular carcinoma. Hepatology 9: 110-115, 1989.

18) Purves LR, Merwe E. Bersohn I. Variants of $\alpha$-fetoprotein. Lancet 2: 464-465, 1970.

19) Smith CJ, Kelleher PC. $\alpha_{1}$-fetoprotein: separation of two molecular variants by affinity chromatography with concanavalin A-agarose. Biochim Biophys. Acta 317: 231-235, 1973.

20) Rouslahti E, Engvall E, Pekkala A, Seppala M. Developmental changes in carbohydrate moiety of human alpha-fetoprotein. Int J Cancer 22: 515$520,1978$.

21) Taketa $K$, Ichikawa E, Taga $H$, Hirai $H$. Antibody affinity blotting: A sensitive techinique for the detection of $\alpha$-fetoprotein separated by lectin affinity electrophoresis in agarose gel. Electrophoresis 6: 492-495, 1985.

22) Ishizuka $H$, Taga $H$, Gotoh I, Arakawa $Y$. The significance of the determination of AFP-isoform in the early diagnosis of hepatocellular carcinoma (HCC). In: Recent Advances in Management of Digestive Cancers, T. Takahashi, Ed. Springer-Verlag., Tokyo, 1993: 622-624. 